\title{
Integrative Treatment of Lung Cancer Patients: Observational Study of 57 Cases
}

\author{
Lorenzo Anelli ${ }^{1,2}$ Alessia Di Nardo ${ }^{2}$ Massimo Bonucci ${ }^{1,2}$ \\ ${ }^{1}$ Integrative Oncology Ambulatory, Nuova Villa Claudia, Rome, Italy \\ Address for correspondence Lorenzo Anelli, MD, Integrative \\ ${ }^{2}$ ARTOI, Rome, Italy \\ Oncology Ambulatory, Nuova Villa Claudia, Rome 00191, Italy \\ (e-mail: Iorenzoanelli@me.com).
}

Asian J Oncol 2021;7:64-75.

\begin{abstract}
Introduction A retrospective clinical study was performed to identify the characteristics of patients with lung cancer treated with integrative cancer treatment in addition to conventional medicine.

Materials and Methods We reviewed medical records for lung cancer patients who visited a single integrative setting in Rome, Italy. A total of 57 patients were included, and the majority had advanced-stage cancer. All of them underwent integrative therapy with nutrition and phytotherapy indications. The diet was designed to reduce most of possible factors promoting cancer proliferation, inflammation, and obesity. Foods with anti-inflammatory, prebiotic, antioxidant, and anticancer properties had been chosen. Herbal supplements with known effects on lung cancer were prescribed. In particular, astragal, apigenine, fucosterol, polydatin, epigallocatechin gallate, cannabis, curcumin, and inositol were used. Furthermore, medical mushrooms and other substances were used to improve the immune system and to reduce chemotherapy side effects. Five key parameters have been evaluated for 2 years starting at the first surgery: nutritional status, immune status, discontinuation of therapy, quality of life, and prognosis of the disease.

Results A relevant improvement in parameters relative to nutritional status, immune

Keywords

- herbal medicine

- integrative oncology

- lung cancer

- nutrition

- oncology status, and quality of life has been observed after integrative therapy compared with the same parameters at the first medical visit before starting such approach.

Conclusion The results suggest that integrative therapy may have benefits in patients with lung cancer. Even though there are limitations, the study suggests that integrative therapy could improve nutritional status and quality of life, with possible positive effect on overall survival.
\end{abstract}

\section{Introduction}

Lung cancer is the most frequently diagnosed cancer, with incidence at $11.6 \%$ and mortality at $18.4 \%{ }^{1}$

Conventional medical treatment could include surgery, radiotherapy, immunotherapy and chemotherapy. Five-year survival after radical surgery is 60 to $80 \%$ at stage I, 40 to $60 \%$ at stage II, and 20 to $40 \%$ at stage III. Non-small cell lung cancer (NSCLC) treatment in advanced stage like IIIB, IIIC, and IV is based on several driver mutations analysis including mutations/alterations of the epidermal growth factor receptor, anaplastic lymphoma kinase, ROS1, and PDL-1 expression. ${ }^{2}$ Chemotherapy is associated with several adverse effects and signs of immediate and delayed toxicity. Immediate side effects could be observed on skin and hair, published online April 14, 2021
DOI https://doi.org/

$10.1055 / \mathrm{s}-0040-1722380$ ISSN 2454-6798. (c) 2021. Spring Hope Cancer Foundation \& Young Oncologist Group of Asia.

This is an open access article published by Thieme under the terms of the Creative Commons Attribution-NonDerivative-NonCommercial-License, permitting copying and reproduction so long as the original work is given appropriate credit. Contents may not be used for commercial purposes, or adapted, remixed, transformed or built upon. (https://creativecommons.org/licenses/by-nc-nd/4.0/).

Thieme Medical and Scientific Publishers Pvt. Ltd. A-12, 2nd Floor, Sector 2, Noida-201301 UP, India 
bone marrow and blood, gastrointestinal tract and kidneys, essential organs such as brain, lungs, and heart.

Grade III or IV neurotoxicity could induce weakness, paresthesia, interfering with function and activities of daily living. In addition, chronic chemotherapy effects include drug resistance, carcinogenicity, and impairment of fertility. Chemotherapy often has low specificity for cancer cells and high toxicity. On the contrary, immunotherapy has less side effects, seems to be much more tolerated, and has a different dose-response curve. ${ }^{3}$

In last decades complementary and alternative medicine is being increasingly adopted in mainstream cancer care to strengthen anticancer effects and to control cancer-related symptoms. Integrative oncology is a patient-centered, evidence-informed field of cancer care that utilizes mind and body practices, natural products, and/or lifestyle modifications from different traditions alongside conventional cancer treatments. Integrative oncology aims to optimize health, quality of life (QoL), and clinical outcomes across the cancer care continuum, and to empower people to prevent cancer and become active participants before, during, and beyond cancer treatment. ${ }^{4}$

\section{Nutrition in Cancer Care}

The lifestyle factors of physical activity, sedentary behavior, and diet are increasingly being studied for their associations with cancer.

Food could influence five key factors in carcinogenesis:

- Epigenetics: some nutrient compounds could be involved in genetic expression, methylation processes and silencing of oncosuppressors..$^{5-8}$

- Gastrointestinal microbiota could act in cancer prevention, in carcinogenesis, and in anticancer therapy. ${ }^{9-11}$

- The inflammation: the increase or the inappropriate expression of chemokines promotes cancer cells survival, proliferation, and metastasis process. ${ }^{10,12}$

- The extracellular acidic $\mathrm{pH}$ of solid tumors ${ }^{13}$

- The key role of IGF-1 on antiapoptotic and mitogenic pathway of many cell types. IGF-1 that stimulates cell cycle progress from G1 to S phase, ${ }^{14}$ is an oncogenic mediator in several tumors, lung cancer included. ${ }^{15,16}$ The obesity could control progression, proliferation, and tumor angiogenesis. ${ }^{17}$ Fat mass and obesity-associated protein (FTO) is increased in human NSCLC, while FTO knockdown represses lung cancer cells growth in vitro and in vivo. ${ }^{18}$

The nutrition could modulate these factors and consequently act on cancer. A diet rich in simple and refined sugar, for example, is involved through aerobic glycolysis in growth and survival of cancer cells..$^{19,20}$ Glucose transporter 1 (GLUT1) activity involves cancer cell development; in lung cancer there is a particular correlation with squamous cancer cells. ${ }^{21}$ The improvement of glucose absorption is a trademark in tumor cells.

Many studies aimed to evaluate the role of glucose and lipid metabolism in growth and survival of cancer cells and investigated the effect of FTO gene in the association between dietary carbohydrates and cancer. ${ }^{22-25}$ Meat and derivatives, milk and derivatives are also evaluated for their effects on tumor growth. The increased intake of milk-based protein through cow's milk consumption $(200-600 \mathrm{~mL}$ ) resulted in a $30 \%$ increase in the IGF-1 serum concentration. ${ }^{26}$ Structural proteins like meat and fish proteins are less efficient in elevating the insulin and IGF-1 plasma concentrations than milk proteins..$^{27,28}$ Milk contains leucine, glutamine, palmitate that promote more than others the activation of mTORC1 (serine and threonine protein kinase that regulates cell growth, proliferation, motility and survival, synthesis protein, and transcription). ${ }^{29,30} 3.9 \%$ of the milk composition is also characterized by fats, $98 \%$ of which by triglycerides, (approximately $65 \%$ of the total is made up of saturated fatty acids, mainly represented by palmitic acid which accounts for approximately $30 \%$ by weight of the total fatty acids, myristic acid and stearic acid. The increase in IGF-1 was also found in meat consumption. ${ }^{31} \mathrm{~A}$ critical review of the meta-analysis found a convincing association between increased red meat intake and cancer, including lung cancer ${ }^{32} \mathrm{~A}$ European prospective survey on cancer and nutrition cohort (EPIC or European Prospective Investigation into Cancer and Nutrition), and further studies highlighted the association between meat consumption and weight gain, fat storage, and inflammatory process. ${ }^{33-35}$ The association found between the consumption of heme iron and lung cancer should also be considered. ${ }^{36-38}$ Individuals with the highest red meat consumption were at $34 \%$ greater risk of lung cancer compared to the lowest consumers in a meta-analysis of 18 cohort studies. ${ }^{38}$ In addition, polyamines (abundant in solanaceae and citrus) seem to allow cancer to function at optimal capacity. Cancer and highly proliferative cells have high levels of polyamines, which have been suggested as supporters of their proliferative capacity, insulin receptor regulators, interacting with some oncogenes. ${ }^{39,40}$

There are foods or herbs that could negatively interfere with different chemotherapies: garlic, ginkgo biloba, echinacea, ginseng, hypericum, soybeans, licorice, pepper, grapefruit, senna, valerian, vitis vinifera, and alcohol. Foods of vegetable origin and fish are preferable to those of animal origin.

Fish proteins compared to other animal proteins could lower high-sensitivity C-reactive protein, a marker of inflammation associated with insulin resistance and type 2 diabetes. ${ }^{41}$ Red meat consumption in high cardiovascular risk population seems to be very high and far from the reccomendations of Mediterranean diet. ${ }^{42}$ High intakes of total and saturated fat could be associated with an increased risk of lung cancer. there are significant differences in the tumor compared with the normal cells in the absorption of $n 3$ polyunsaturated fatty acid (PUFA) and in the generation of reactive species from PUFA. ${ }^{43}$ Polyunsaturated fatty acids could improve survival during chemotherapy, ${ }^{44,45}$ causing normal cells to produce greater quantities of resolvins and protect themselves from anticancer drugs. ${ }^{43}$ The protective effects of almonds, hazelnuts, pistachios, walnuts, and many seeds are mainly attributable to PUFAs: nut consumption is inversely related to all the main histological subtypes of lung cancer, ${ }^{46}$ while almonds can help to control blood 
sugar ${ }^{47}$ and this could have a positive effect on tumor control. Vegetables and fruit are very rich in anthocyanins, carotenoids, vitamin C, chlorophyll, carotenoids, folic acid, lutein, polyphenols, flavonoids, sulfur compounds, lycopene, phycocyanins, and monogalactosyl diacylglycerol, all protective compounds against inflammation, oxidative stress, acidification, for an environment unfavorable to tumor survival and favorable for the immune system. ${ }^{48}$ Indole- 3 carbinol, surfuraphane, ${ }^{49}$ isothiocyanates, ${ }^{50-52}$ epigallocatechin gallate (EGCG), ${ }^{53}$ chlorogenic acid, ${ }^{54}$ and compounds present in vegetables, mainly cruciferous, have been shown to have proapoptotic, anti-inflammatory, and antitumor action.

Phenolic acids, flavanols, flavones, isoflavones, anthocyanins, and condensed tannins, have been identified and characterized in legumes (that seems to be protective and are an important protein source). The fibers contained in previous foods are essential for the fermentation and maintenance of a good gut microbiota, with positive effects on cancer: intestinal fermentation of dietary fiber by members of the colon microbiota causes the generation of several short chain fatty acids including acetic, propionic, and butyric acids with anti-inflammatory ${ }^{55}$ and immunostimulant ${ }^{53}$ effects. Dietary fibers are contained in whole grains, reason why they are preferred over refined ones. It is fundamental to completely exclude any form of refined cereal even because of its high GI capable of influencing the etiology of lung cancer. ${ }^{56}$ The consumption of ancient grains gives more benefits compared with the modern ones: significant reduction of total cholesterol; low-density lipoprotein cholesterol and blood sugar; significant increase in circulating endothelial progenitor cells; increase in DHA and selenium; reduced fasting insulin levels; improvement of the microbiota. ${ }^{57,58}$

\section{Phytotherapeutics for Lung Cancer}

There are phytotherapeutically active ingredients, now confirmed by scientific literature, active directly on lung cancer cells.

- Curcumin (Curcuma longa polyphenol) is able to regulate oncogenes, ${ }^{59}$ inhibits the invasion and metastasis of cancer cells, ${ }^{59-61}$ inhibits their growth by suppressing vascular endothelial growth factor (VEGF) and NF-kB (important for the production of inflammatory cytokines and for the activation of the inflammasome) ${ }^{58}$ Curcumin potently inhibits the growth of NCI-H460, NCI-H446, 62 and NSCLC A549 cells by inducing both apoptosis and autophagy by inhibiting the PI3K/Akt/mTOR pathway ${ }^{63}$ by demonstrating cytotoxic activity against NSCLC. ${ }^{64}$ It can improve anticancer immunity by regulating tumor-specific immune tolerance. ${ }^{65}$ The synergistic effect with chemotherapy is also significant ${ }^{66}$ with anti-inflammatory and antioxidant activities $^{59}$ even after radio and chemotherapy, and with cytoprotective effects for normal tissues. ${ }^{67}$

- EGCG is the most abundant polyphenol in green tea. It has an antioxidant power stronger than vitamin $\mathrm{E}^{68}$; it has remarkable properties on lung cancer cells ${ }^{69}$ : inhibition of PD-L1 expression, ${ }^{70}$ inhibition of cell proliferation, ${ }^{71}$ potentiation of erlotinib, ${ }^{71}$ suppression of resistance to multiple drugs such as that for etoposide, ${ }^{72}$ increase in growth inhibition, redistribution of the cell cycle, and increase in the rate of apoptosis concomitantly with cisplatin. ${ }^{73}$

- Another phytotherapeutic principle active on lung cancer is inositol: clinical studies in humans have indicated that inositol hexaphosphate is able to improve the anticancer effect of conventional chemotherapy, to control tumor metastases and improve the QoL. ${ }^{74}$ Its antitumorigenic effects on lung cancer cells could include a reduction in the expression of mutant KRAS, a change in the tumor microenvironment through the recruitment of polarized (M1-like) macrophages at tumor sites and regulation of interleukin-6 (IL-6) secretion. ${ }^{75}$

- The polysaccharide astragalus (APS), isolated from the root of the Astragalus membranaceus, used in Traditional Chinese Medicine, can suppress human non-small cell cancer cells by downregulating p65 and p50, reducing the transcription of NF-KB (active in NSCLC) and reducing the level of Bcl-xL protein expression in A549 cells ${ }^{76}$; APS induces apoptosis by blocking the ERK pathway in $\mathrm{NSCLC}^{77}$ and NSCLC H460 cells through suppression of notch 1 and notch 3 and subregulation of Bcl-2, ${ }^{78}$ increases proapoptotic Bax levels (activation of caspase- 3 and caspase-9 in H1299 cells). ${ }^{79,80}$

- Apigenin is a flavonoid with several properties: it is antioxidant, proapoptotic, ${ }^{81,82}$ and causes ROS accumulation with apoptosis induction of approximately $30 \%$ in cancer cells pulmonary H1299, H460, and H2030. It is anticarcinogenic ${ }^{81}$ : the secretion of tumor necrosis factor- $\alpha$ (TNF- $\alpha$ ) has been reduced by approximately $60 \% 33$; it suppresses the expression of glycolytic GLUT1 in lung cancer cells A549 (carcinoma lung), H460 (lung cancer), H2030 (lung adenocarcinoma). ${ }^{84}$ Apigenin has a significant anti-inflammatory activity ${ }^{81}$ : blocks the secretion of IL-6 and IL-10. ${ }^{83}$ It exerts an antiproliferative ${ }^{81}$ and antiprogressive action on lung cancer cells A549 ${ }^{83}$ suppressing the expression of VEGF in angiogenesis through degradation of the HIF- $1 \alpha$ protein. ${ }^{85}$

- The polydatin inhibits the cell proliferation of both A549 and H1299 in a dose-dependent way, suppresses the migration of NSCLC cells, suppresses the NF- $\mathrm{KB}$ pathway in NSCLC cells ${ }^{86}$ and cell proliferation in the $S$ phase.$^{87}$ It was found that $6 \mu \mathrm{moL}$ PD caused 65\% (48 hours) loss of cell viability in A549 lung cancer cells, 66\% (48 hours) loss in NCI-H1975 lung cancer cells and 28\% in human bronchial epithelial (HBE) cells derived from normal HBE cells, suggesting that polydatin is more potent in eliminating cancer cells than noncancer cells. It causes apoptosis for the increase of Bax expression ${ }^{87}$ and for glucose-6-phosphate dehydrogenase (G6PD) inhibition, causing the accumulation of reactive oxygen species. ${ }^{88}$ It seems effective in patients with NSCLC treated with afatinib because of its anti-inflammatory activity in epidermal keratinocytes. ${ }^{89}$

- Fucosterol (marine algae phytosterol) has anticancer properties on lung cancer cells: it has apoptotic effect ${ }^{90}$ with an increase in Bax, triggering the arrest in $\mathrm{G} 2 / \mathrm{M}$ of the cell cycle of cells A549 and SK-LU-1; it is associated with the reduction of the expression of CDC2, Cyclin A, Cyclin B1, and upregulation of the negative regulators of cell cycle progression 
(p21Cip1 and p27Kip1). ${ }^{91}$ Fucosterol has shown an increase in antioxidant defense ${ }^{92}$ with the suppression of nitric oxide synthase (iNOS) ${ }^{93}$; the anti-inflammatory effects of fucosterol are associated with the suppression of the NF-KB and p38 MAPK pathways. ${ }^{93,94}$

\section{Phytotherapeutics with Immunostimulant Activity}

In addition to herbal medicine directly active on cancer, there are other substances that can stimulate the immune system of patients with lung cancer. Mushrooms, for example, are widely used in traditional Chinese medicine.

Shiitake, reishi, and maitake mushrooms have immunostimulating and immunomodulating properties thanks to the $\beta$-glucans of the cell walls, the so-called PAMP (pathogen-associated molecular patterns) involved in initiating an immune response: it binds to TLR2 by initiating adaptive immunity and PAMP- pattern recognition receptors on monocytes, dendritic cells, granulocytes, and NK cells of the innate immune system leading to the activation of immune cells, production of cytokines, and expression of adhesion molecules. ${ }^{95}$

The Japanese shiitake mushroom, particularly used, is rich in lentinan polysaccharide associated with the proliferation of peripheral blood mononuclear cells, with the increase in the salivary production of immunoglobulins $A$ and the increase in the amount of circulating B cells. ${ }^{96}$ It causes in vitro secretion of various cytokines ${ }^{95}$ and increases the effectiveness of chemotherapy for lung cancer. ${ }^{97}$ The MD-fraction (glucan purified by the maitake) increases body weight, spleen weight, and the number of immunocompetent cells such as macrophages, dendritic cell (DC), and NK cells in mice treated with cisplatin, and increase the number of colony-forming unit for granulocytes and macrophages colonies in the bone marrow. ${ }^{98}$

Ganoderma lucidum(reishi) involves stimulating T cells and inflammatory response by expression and production of chemokines $^{95}$; a significant increase in B cell population has been found. ${ }^{99}$

Ganoderma frondosa(maitake) extracts enhance the action of immune cells including macrophages, natural killer (NK) cells, and cytotoxic T cells against cancer cells. ${ }^{96}$ Grifolan promotes macrophage activities by increasing the production of IL-1, IL-6, and IL-8, activating and increasing the number of leukocytes. ${ }^{95}$

The immune role of vitamin $\mathrm{D}$ is also significant: in addition to controlling lung cancer by favorably altering the microenvironment of the tumor, ${ }^{100,101}$ it stimulates the immune system ${ }^{100,102}$ : it is directly related to the stimulation of B and T cells. ${ }^{103}$ Cytokines secreted by vitamin D-treated dendritic cells are significantly more potent in driving T-cell differentiation. ${ }^{104}$

Melatonin could prevent or minimize the unfavorable effects of radiotherapy on blood cell count and has potential protective effects on bone marrow. ${ }^{105-107}$

\section{Phytotherapeutics for Adverse Effects}

There are numerous herbal therapies that could mitigate the side effects of chemotherapy for lung cancer.
Ginger is able to reduce nausea and vomiting caused by chemotherapy ${ }^{108-110}$ through the inhibitory effect of gingerols and shogaols (the main chemical components of ginger) on M3 and 5-HT3 receptors. ${ }^{111}$

Peripheral neurotoxicity is one of the main complications associated with the use of chemotherapy agents such as platinum compounds, taxanes, and vinca alkaloids. Acetyl L-carnitine could have neuroprotective and neurotrophic properties, antioxidant activity, positive actions on mitochondrial metabolism, and stabilization of intracellular membranes; it determines the recovery of nerve conduction velocity, ${ }^{112,113}$ could restore the mechanical nociceptive threshold, and induces analgesia with efficacy and high tolerability in the treatment of peripheral neuropathy induced by chemotherapy (CIPN or chemotherapy-induced peripheral neuropathy $)^{112}$ such as paclitaxel and cisplatin. ${ }^{114}$

American Ginseng is useful against fatigue: for a long time used in traditional Chinese medicine as a natural energy booster, the active ingredients of ginseng, called ginsenosides, reduce inflammation-related cytokines and help regulate cortisol levels by improving related symptoms to cancer fatigue including pain, appetite, and quality improvement. ${ }^{115}$

The joint pains resulting from the treatments can be alleviated with the natural Boswellia serrata (BSE). It has anti-inflammatory, antiarthritic activity. ${ }^{116,117}$ It can reduce joint pain and improve physical functional capacity. ${ }^{116}$ Boswellia is able to prevent, treat, repair, reduce damage, or control connective tissues inflammation. It protects cartilage or reduce symptoms associated with damage to connective tissue. ${ }^{118}$

Finally, with regard to oral mucositis from chemotherapy, data from a series of cases of patients undergoing radiotherapy/chemotherapy have suggested that the use of prophylactic hyaluronic acid can be effective, ${ }^{119}$ even more if combined with Lapacho, ${ }^{120}$ avoiding the use of sweet mouthwashes.

The clinical study has evaluated the efficacy of integrative medicine with nutrition and phytotherapy on lung cancer patients.

\section{Materials and Methods}

\section{Ambulatorial Phase}

A total of 57 lung cancer patients, 25 males and 32 females, were included. Their age was in the range of 39 to 89 years. The majority of cancers were adenocarcinomas. The extent of the tumor, the presence of pleural effusion, the presence or absence of metastasis, the number of other organs involved, the diversity of lung lesions, the lymph node involvement, the presence or absence of liver, brain and bone metastases made the treatment group heterogeneous. The primary tumor was in the lung and they all started the integrated therapy in association with the conventional therapy already ongoing.

At each medical evaluation, five basic parameters were analyzed: nutritional status (SN), immune status (SI), QoL, discontinuation of conventional therapy (IT), and disease prognosis (PM). 
SN was analyzed by the investigation of nutritional values from blood tests: liver, kidney, thyroid, nervous and bone system function, hemostasis, coagulation and hemodynamics efficiency, hematocrit, glucose and lipid metabolism, protein turnover, serum mineral levels, and vitamins.

SI was analyzed by blood tests, with the number of basophils, eosinophils, neutrophils, and monocytes. Lymphocyte typing is fundamental.

The QoL investigation was based on the presence and number of side effects.

The prognosis of the disease was assessed by diagnostic reports with the analysis of four parameters: reduction of lesions, stability, increase of lesions, and new metastasis.

The integrative approach consisted of the following:

- dietetic prescription ( - Table $\mathbf{1}$ ).

- phytotherapeutic prescription (-Table 2).

\section{Analytical Phase}

We reviewed medical records for lung cancer patients who visited our integrative clinical setting between 2014 and 2019. All patients were visited after 3 to 4 months. The effects of integrative cancer treatment were observed for 2 years. At the first medical evaluation and at every medical control a score was given for every parameter analyzed (-Table $\mathbf{3}$ ).

The average of each score was calculated for every parameter using the Excel spreadsheet: on the first visit, the 3-month check, the 6-month check, the 1-year check, and the 2-check years. In this way it was possible to observe which score at each visit was predominant and with what percentage, to deduce the condition of the different parameters during the therapy. The whole treatment group (57 patients) performed a 3-month check-up; 39 patients guaranteed the control at 6 months; 23 were also observed at 1 year and 12 even at 2 years. All 57 patients were contacted after the study to find out the reason for the dispersion of the treatment group (death or other causes).

\section{Results}

We analyzed the percentages of the scores ${ }^{1-3}$ relative to the nutritional status of the treatment group at the first visit and at the checks at 3, 6, 12, 24 months (-Table 4).

The scores relative to the immune status of the treatment group were evaluated ( $\mathbf{- T a b l e ~} \mathbf{5}$ ).

The scores relative to the QoL in the treatment group at the first visit and subsequent visits were evaluated ( - Table 6 ).

Another evaluation was about the interruption of conventional therapies ( $\mathbf{- T a b l e ~} \mathbf{7}$ ).

The prognosis of the disease in the treatment group was evaluated ( -Table 8).

An evaluation of the life expectancy was performed (-Table 9).

Table 1 Suggested and not allowed food

\begin{tabular}{|c|c|}
\hline Food not allowed & Suggested food \\
\hline $\begin{array}{l}\text { Red meat, white meat (possible use of organic } \\
\text { chicken or rabbit only for necessary psychological } \\
\text { support) } \\
\text { Milk and dairy products } \\
\text { Soy } \\
\text { Solanaceae } \\
\text { Large fish } \\
\text { Refined and simple sugars (the fruit is allowed only } \\
\text { one portion per day, whole, without extraction) } \\
\text { Complex sugars such as bread and pasta with } \\
\text { refined flours }\end{array}$ & $\begin{array}{l}\text { Legumes, eggs ( } 2 \text { per week) } \\
\text { Fish: anchovies, cod, sardines, mackerel, sole, red snapper, wild salmon, sea bass, } \\
\text { sea bream (not bred), small tuna } \\
\text { Fresh seasonal vegetables, especially cruciferous vegetables: cabbage, cauliflower, } \\
\text { broccoli, sauerkraut, and savoy cabbage } \\
\text { Organic whole grains, ancient grains, Khorasan, spelled, buckwheat, brown or } \\
\text { basmati rice, naturally leavened bread } \\
\text { Dried fruit: almonds, walnuts, pistachios, hazelnuts, pine nuts, and seeds, sesame } \\
\text { seeds } \\
\text { Leaves of celery and parsley } \\
\text { Vegetable milk: oats, almond, rice, donkey, spelled. No sugars, salt, and vegetable } \\
\text { oils should be added } \\
\text { Vegetable protein supplements } \\
\text { Vitamin supplements } \\
\text { Iron supplements } \\
\text { Calcium supplements: calcium orotate }\end{array}$ \\
\hline
\end{tabular}

Abbreviation: PUFA, polyunsaturated fatty acid.

Table 2 Phytotherapeutics and integrative therapies

\begin{tabular}{|l|l|l|}
\hline Medicinal mushrooms: agaricus & Astragalus & American ginseng \\
reishi, maitake, shitake & Epigallocatechin-gallate & Ginger \\
Vitamin D & Curcumin & Colostrum \\
Tamarix Gallica & Fucosterol & melatonin \\
Melatonin & Apigenin & probiotics \\
& Inositol & Boswellia \\
& Aloe vera & Acetyl L-Carnitine \\
& & Lapacho \\
\hline
\end{tabular}


Table 3 Parameters for the study

\begin{tabular}{|c|c|c|c|c|}
\hline Nutritional status & Immune system & Quality of life & $\begin{array}{l}\text { Discontinuation of } \\
\text { chemotherapy }\end{array}$ & Cancer prognosis \\
\hline $\begin{array}{l}\text { 3: all parameters in the } \\
\text { range } \\
\text { 2: one altered value } \\
\text { 1: more than one param- } \\
\text { eter altered }\end{array}$ & $\begin{array}{l}\text { 3: all parameters in the } \\
\text { range } \\
\text { 2: one altered value } \\
\text { 1: more than one param- } \\
\text { eter altered }\end{array}$ & $\begin{array}{l}\text { 3: no adverse effects } \\
\text { 2: one adverse effect } \\
\text { 3: more than one } \\
\text { adverse effect }\end{array}$ & $\begin{array}{l}\text { 3: no discontinuation } \\
\text { 2: one discontinuation } \\
\text { 1: more than one } \\
\text { discontinuation }\end{array}$ & $\begin{array}{l}\text { 4: reduction of the } \\
\text { lesions } \\
\text { 3: stable disease } \\
\text { 2: increase of the lesions } \\
\text { 1: new metastasis }\end{array}$ \\
\hline
\end{tabular}

Table 4 Results of the percentages of the scores $(3,2,1)$ relative to the nutritional status of the treatment group: at the first visit and checks at 3, 6, 12, 24 months

\begin{tabular}{|c|c|c|c|}
\hline & $\begin{array}{l}\text { Score } 3 \\
\text { All parameters in ranges }\end{array}$ & $\begin{array}{l}\text { Score } 2 \\
\text { Only one parameter out } \\
\text { of range }\end{array}$ & $\begin{array}{l}\text { Score } 1 \\
\text { More than } 1 \text { parameter } \\
\text { out of range }\end{array}$ \\
\hline $\begin{array}{l}\text { First visit of patients evaluated at } 3 \mathrm{mo} \\
(57 \mathrm{pts})\end{array}$ & $66.66 \%{ }^{38}$ & $22.80 \%^{13}$ & $10.52 \%^{6}$ \\
\hline Medical evaluation at $3 \mathrm{mo}$ (57 pts) & $77.18 \%^{129}$ & $19.29 \% 11$ & $3.50 \%^{2}$ \\
\hline $\begin{array}{l}\text { First visit of patients evaluated at } 6 \text { mo } \\
\text { (39 pts) }\end{array}$ & $66.66 \% 25$ & $25.64 \%{ }^{10}$ & $7.69 \%^{3}$ \\
\hline Medical evaluation at 6 mo (39 pts) & $79.48 \%{ }^{31}$ & $17.94 \%^{7}$ & $2.56 \%$ \\
\hline $\begin{array}{l}\text { First visit of patients evaluated at } 12 \\
\text { mo ( } 23 \text { pts) }\end{array}$ & $69.56 \%{ }^{16}$ & $21.73 \%^{5}$ & $8.69 \%^{2}$ \\
\hline Medical evaluation at $12 \mathrm{mo}$ (23 pts) & $78.26 \% 17$ & $18.18 \%^{4}$ & $4.34 \%^{1}$ \\
\hline $\begin{array}{l}\text { First visit of patients evaluated at } 24 \\
\text { mo ( } 12 \text { pts) }\end{array}$ & $75 \%^{9}$ & $16.66 \%^{2}$ & $8.33 \%^{1}$ \\
\hline Medical evaluation at $24 \mathrm{mo}$ (12 pts) & $75 \%^{9}$ & $25 \%^{3}$ & $0 \%(0)$ \\
\hline
\end{tabular}

Table 5 Results of the percentages of the scores $(3,2,1)$ relative to the immune status of the treatment group: at the first visit and checks at 3, 6, 12, 24 months

\begin{tabular}{|l|l|l|l|}
\hline & $\begin{array}{l}\text { Score } 3 \\
\text { All parameters in } \\
\text { ranges }\end{array}$ & $\begin{array}{l}\text { Score } 2 \\
\text { Only one parameter } \\
\text { out of range }\end{array}$ & $\begin{array}{l}\text { Score } 1 \\
\text { More than } 1 \text { parameter } \\
\text { out of range }\end{array}$ \\
\hline First visit of patients evaluated at 3 mo (57 pts) & $19.29 \%^{11}$ & $47.36 \%^{27}$ & $33.33 \%^{18}$ \\
\hline Medical evaluation at 3 mo (57 pts) & $50.87 \%^{29}$ & $36.84 \%^{20}$ & $12.28 \%^{7}$ \\
\hline First visit of patients evaluated at 6 mo (39 pts) & $15.38 \%^{6}$ & $46.15 \%^{17}$ & $38.46 \%^{15}$ \\
\hline Medical evaluation at 6 mo (39 pts) & $58.97 \%^{22}$ & $38.46 \%^{15}$ & $2.56 \%^{1}$ \\
\hline First visit of patients evaluated at $12 \mathrm{mo}(23 \mathrm{pts})$ & $17.39 \%^{4}$ & $43.47 \%^{10}$ & $39.13 \%^{9}$ \\
\hline Medical evaluation at $12 \mathrm{mo}(23 \mathrm{pts})$ & $73.91 \%^{129}$ & $17.39 \%^{4}$ & $8.69 \%^{2}$ \\
\hline First visit of patients evaluated at $24 \mathrm{mo}(12 \mathrm{pts})$ & $25 \%^{3}$ & $41.66 \%^{5}$ & $33.33 \%^{4}$ \\
\hline Medical evaluation at $24 \mathrm{mo}(12 \mathrm{pts})$ & $83.33 \%^{10}$ & $16.66 \%^{2}$ & $0 \%^{2}(0)$ \\
\hline
\end{tabular}

\section{Discussion}

The integrated treatment of the study gave good results in all of the five parameters evaluated. Regarding the nutritional status, although $66.66 \%$ of the treatment group started with an optimal status (score 3 ) at the first visit, nutritional deficiencies were found (low values of vitamin D, C, A of group $\mathrm{B}$; low values of iron, low protein intake, low omega 3). After the integrated intervention, compared with the first visit, the optimal state (score 3 ) increased $+10.52 \%$ after 3 months, + $12.82 \%$ after 6 months, $+8.70 \%$ after 1 year, returning as the first visit in 2 years (-Table 4 ). The critical state (score 1 ) improved by $7.02 \%$ at the first check, $5.13 \%$ after 6 months, and $4.35 \%$ after 1 year.
A frequent course among cancer patients is characterized by cachexia, dysphagia, nausea, vomiting, diarrhea, oral complications, and dysgeusia. ${ }^{121}$ The diet prescribed in the study was able to optimize nutritional status. None of patients whom had followed this treatment for 24 months had score 1 at at nutritional status, contrasting the typical worsening of the disease. The diet is balanced in proteins (fish, egg, and legumes), carbohydrates (whole grains and ancient low-GI grains) and polyunsaturated fatty acids, fiber, antioxidants, and vitamins (vegetables, fruit, legumes, dried fruit). There were patients that declared to have reduced the assiduity in the application of dietary rules for psychological reasons, ${ }^{122}$ not for impossibility. 
Table 6 Results of the percentages of the scores $(3,2,1)$ relative to the quality of life in the treatment group: at the first visit and checks at 3, 6, 12, 24 months

\begin{tabular}{|l|l|l|l|}
\hline & $\begin{array}{l}\text { Score } 3 \\
\text { No adverse effects }\end{array}$ & $\begin{array}{l}\text { Score } 2 \\
\text { One symptom }\end{array}$ & $\begin{array}{l}\text { Score } 1 \\
\text { More than one } \\
\text { symptom }\end{array}$ \\
\hline First visit of patients evaluated at 3 mo (57 pts) & $43.85 \%^{24}$ & $26.31 \%^{15}$ & $29.82 \%^{129}$ \\
\hline Medical evaluation at 3 mo (57 pts) & $70.17 \%^{40}$ & $17.54 \%^{10}$ & $12.28 \%^{7}$ \\
\hline First visit of patients evaluated at 6 mo (39 pts) & $46.15 \%^{17}$ & $28.20 \%^{11}$ & $25.64 \%^{10}$ \\
\hline Medical evaluation at 6 mo (39 pts) & $74.35 \%^{29}$ & $12.82 \%^{5}$ & $12.82 \%^{5}$ \\
\hline First visit of patients evaluated at 12 mo (23 pts) & $43.47 \%^{10}$ & $30.43 \%^{7}$ & $26.08 \%^{6}$ \\
\hline Medical evaluation at 12 mo (23 pts) & $73.91 \%^{129}$ & $17.39 \%^{4}$ & $8.69 \%^{2}$ \\
\hline First visit of patients evaluated at 24 mo (12 pts) & $58.33 \%^{7}$ & $16.66 \%^{2}$ & $25 \%^{3}$ \\
\hline Medical evaluation at 24 mo (12 pts) & $66.66 \%^{8}$ & $33.33 \%^{4}$ & $0 \%^{4}(0)$ \\
\hline
\end{tabular}

Table 7 Results of the percentages of the scores $(3,2,1)$ on the entire treatment group relative to the interruption of conventional therapies: the first visit and medical evaluation at 3, 6, 12, 24 months

\begin{tabular}{|l|l|l|l|}
\hline & $\begin{array}{l}\text { Score 3 } \\
\text { No discontinuation }\end{array}$ & $\begin{array}{l}\text { Score 2 } \\
\text { One discontinuation }\end{array}$ & $\begin{array}{l}\text { Score 1 } \\
\text { More than one } \\
\text { discontinuation }\end{array}$ \\
\hline Total sample $^{56}$ & $94.74 \%^{51}$ & $5.26 \%^{3}$ & $0 \%(0)$ \\
\hline
\end{tabular}

Table 8 Results relating to the percentages of the scores ${ }^{1-4}$ relating to the prognosis of the disease in the treatment group after the start of the integrated therapy: control at 3, 6, 12, and 24 months

\begin{tabular}{|l|l|l|l|l|}
\hline & $\begin{array}{l}\text { Score } 4 \\
\text { Reduction of } \\
\text { the lesions }\end{array}$ & $\begin{array}{l}\text { Score } 3 \\
\text { Stable } \\
\text { disease }\end{array}$ & $\begin{array}{l}\text { Score } 2 \\
\text { Increase of } \\
\text { the lesions }\end{array}$ & $\begin{array}{l}\text { Score } 1 \\
\text { New } \\
\text { metastasis }\end{array}$ \\
\hline Medical evaluation at 3 mo for all patients $(57 \mathrm{pts})$ & $47.36 \%^{27}$ & $36.84 \%^{20}$ & $10.52 \%^{6}$ & $5.26 \%^{3}$ \\
\hline Medical evaluation at 3 mo for patients evaluated at 6 mo (39 pts) & $41.02 \%^{16}$ & $41.02 \%^{16}$ & $10.25 \%^{4}$ & $7.69 \%^{3}$ \\
\hline Medical evaluation at 6 mo for patients evaluated at 6 mo (39 pts) & $41.02 \%^{16}$ & $35.89 \%^{14}$ & $12.82 \%^{5}$ & $10.25 \%^{4}$ \\
\hline Medical evaluation at 3 mo for patients evaluated at 12 mo (23 pts) & $43.37 \%^{10}$ & $34.78 \%^{8}$ & $13.04 \%^{3}$ & $8.69 \%^{2}$ \\
\hline Medical evaluation at 12 mo for patients evaluated at 12 mo (23 pts) & $30.43 \%^{7}$ & $34.78 \%^{8}$ & $30.43 \%^{7}$ & $4.34 \%^{1}$ \\
\hline Medical evaluation at 3 mo for patients evaluated at $24 \mathrm{mo}(12 \mathrm{pts})$ & $41.66 \%^{5}$ & $25 \%^{3}$ & $16.66 \%^{2}$ & $16.66 \%^{2}$ \\
\hline Medical evaluation at 24 mo for patients evaluated at $24 \mathrm{mo}(12 \mathrm{pts})$ & $50 \%^{6}$ & $16.66 \%^{2}$ & $16.66 \%^{2}$ & $16.66 \%^{2}$ \\
\hline
\end{tabular}

Table 9 Assessment of life expectancy, from the discovery of the disease until February 2, 2020, after having contacted all the patients, even those missing in the study

\begin{tabular}{|l|l|l|l|l|l|l|l|l|}
\hline & 9 mo & Over 1 y & Over 2 y & Over 3 y & Over 4 y & Over 5 y & Over 6 y & Over 7 y \\
\hline $\begin{array}{l}\text { Alive } \\
34 \text { pts (59.64\%) }\end{array}$ & 2 & 8 & 8 & 6 & 5 & 3 & 1 & 1 \\
\hline $\begin{array}{l}\text { Lost at follow-up } \\
13 \text { pts (22.80\%) }\end{array}$ & & & & & & & & \\
\hline $\begin{array}{l}\text { Dead pts } \\
10 \text { pts (17.54\%) }\end{array}$ & & 3 & 3 & 2 & 2 & 0 & 0 & 0 \\
\hline Survival percentage & $3.50 \%$ & $19.29 \%$ & $19.29 \%$ & $14.56 \%$ & $12.28 \%$ & $5.26 \%$ & $1.75 \%$ & $1.75 \%$ \\
\hline
\end{tabular}

The diet appeared anti-inflammatory, immunostimulating, antioxidant, and antiproliferative.

Before integration, the immune status of the very critical group (score 1) was 33.33\% (below the reference values: platelets, NK cells, T4 lymphocytes and T8 lymphocytes). At the controls after integrated therapy, the score 1 dropped:
21.05\% after 3 months, 35.90\% at 6 months, 30.44\% at 1 year, and complete elimination of critical issues at 2 years. Therefore, the immune status with supplementation had a positive course: $+31.58 \%$ after 3 months, $+43.59 \%$ after 6 months, $+56.52 \%$ after 1 year, and $+58.33 \%$ after 2 years (all compared with the first visit) ( - Table 5 ). 
Tumors develop several methods to avoid and inhibit the function of immune cells. ${ }^{123}$ Chemotherapy not only acts on cancer cells, but also attacks blood cells, counteracting the natural antitumor response. ${ }^{124,125}$

It is essential to improve the weakened immune status to better fight cancer cells synergically with chemotherapy and radiotherapy.

The QoL significantly improved after natural phytotherapy acting on the symptoms of adverse effects.

The following substances have been prescribed: ginger, Boswellia, acetyl L-carnitine, American ginseng, Lapacho, melatonin, polydatin.

At the first visit, $29.82 \%$ of patients had more than one side effect, with a low QoL. After 3 months there was a reduction in this state of malaise: $17.54 \%, 12.82 \%$ at 6 months, $17.39 \%$ after 1 year, and total reset of the low QoL at 2 years. On the other hand, there was an increase in $\mathrm{QoL}$ improvement of $+26.32 \%$ at 3 months, $+28.20 \%$ at 6 months, $+30.44 \%$ at 1 year, $+8.33 \%$ at 2 years (-Table 6 ). At 2 years the improvement was lower, but that could be because of the adverse effects of the new lines of therapies taken. In any case, even at 2 years follow-up all cases of low QoL have shifted toward mediocre and good conditions. QoL is a determining factor in allowing patients to better deal with therapies, both physically and psychologically. ${ }^{126}$ The improvement of nutrition, immunity, and QoL ensured the continuity of conventional therapies: $94.74 \%$ of the sample did not have to make any interruption of therapy (- Table 7), thus maintaining an advantage over the tumor compared with a worsening due to interruptions. ${ }^{127}$ The improvement of the previous factors combined with the integration with other phytotherapeutics such as astragalus, apigenin, epigallocatechin-gallate, inositol, fucosterol, polydatin, and aloe (anti-inflammatory, antioxidants, antiproliferative, antimetastatic, proapoptotic, synergistic effects) could have been decisive in improving the prognosis of cancer. In the follow-up there was a reduction in the lesions: $+47.36 \%$ at 3 months. At 6 months and 1 year, compared with 3 months, the reduction of the lesions stopped, while there was an increase of the lesions $(+2.57 \%$ at 6 months, $+17.39 \%$ at 1 year) and new metastases ( $+2.56 \%$ at 6 months).

Integrated therapy, together with conventional therapy, has shown a significant advantage over the tumor, letting prevail cases of reduction and stability of the lesions guaranteeing a good life expectancy. The estimated survival time of small cell lung cancer is 20 months with a 5-year survival rate of $20 \%$ and $<1 \%$ for SCLC (small cell lung cancer). For NSCLC, the 5 -year survival rate of patients varies by stage, from 60 to $70 \%$ in stage I patients to $<1 \%$ in patients with stage IV disease. ${ }^{128}$ According to estimates of Global Cancer Observatory relating to lung cancer survival in several European states, out of a total sample, approximately 39\% have 1-year survival, $19.30 \%$ of survivors are likely to achieve 3 years. In our treatment group patients at stage IV were 34 and those at stage II and III were 18. Even though in the study there are only 12 controls at 2 years, after the recall of the whole treatment group at the end of the study, it has been shown that the dispersion of the sample over the years was not caused only by deaths but mainly for other reasons.

Considering the onset of the disease for all patients, and also that the design of the current study is subject to limitations, it is possible to say that integrated therapy, together with the conventional one, ensured 1-year survival of $74.18 \%$ of treatment group, 2-year survival of 54.89\%, 3-year survival of $35.6 \%$, and 4 -year survival at $21.04 \%$. At 5 years, $8.76 \%$ of patients survived, 6- and 7-year survival was $1.75 \%$ in both cases ( $\mathbf{- T a b l e ~} \mathbf{9}$ ).

Patients independently followed mind-body disciplines, acupuncture, and hyperthermia as additional support to the therapy. Such disciplines were not considered as observational parameters in the study. Almost all patients, even those missing in the study, who confirmed survival to date, despite the interruption of the controls, continued autonomously the integration with phytotherapy and they all continued the diet as a lifestyle, although not in a perfect way.

\section{Conclusion}

Integrated therapy, as a support for conventional therapy, is a new approach to consider for lung cancer patients. Through nutrition (with anti-inflammatory, immunomodulating antioxidant, antiproliferative effects) and targeted phytotherapeutic support, integrated therapy was able to improve the nutritional status, immune status, and QoL in patients with lung cancer. This guaranteed the continuity of the therapies without interruptions and an advantage over the disease thanks to the combined action of chemotherapy/biological drugs, food and phytotherapy, all without any interference. The result was a good prognosis for the disease and a good survival, even for stage IV cases. Thus, further cohort studies with a rigorous prospective study design are required.

\section{Conflict of Interest}

None declared.

\section{References}

1 Globocan. Available at: https://gco.iarc.fr/today/online-analysis-pie. Accessed November 30, 2020

2 Aiom: Associazione Italiana di Oncologia Medica. Linee guida neoplasie del polmone; 2019. Available at: https://www.aiom. it/wp-content/uploads/2019/10/2019_LG_AIOM_Polmone-1. pdf. Accessed November 30, 2020

3 Schirrmacher V. From chemotherapy to biological therapy: a review of novel concepts to reduce the side effects of systemic cancer treatment (Review) Int J Oncol 2019;54(2): 407-419

4 Witt, CM, Balneaves, LG, Cardoso, MJ, Cohen, L, Greenlee, H, Johnstone, P, Kücük, Ö, Mailman, J, Mao, JJ. Una definizione completa di oncologia integrativa, Monografie JNCI. Numero 2017;52: $\lg x 012$

5 Hurlimann T, Menuz V, Graham J, Robitaille J, Vohl MC, Godard B. Risks of nutrigenomics and nutrigenetics? What the scientists say. Genes Nutr 2014;9(1):370

6 Nielsen DE, El-Sohemy A. A randomized trial of genetic information for personalized nutrition. Genes Nutr 2012;7(4):559-566 
7 Nasir A, Bullo MM, Ahmed Z, et al. Nutrigenomics: epigenetics and cancer prevention: a comprehensive review. Crit Rev Food Sci Nutr 2020;60(8):1375-1387

8 Elsamanoudy AZ, Mohamed Neamat-Allah MA, Hisham Mohammad FA, Hassanien M, Nada HA. The role of nutrition related genes and nutrigenetics in understanding the pathogenesis of cancer. J Microsc Ultrastruct 2016;4(3): $115-122$

9 Vivarelli S, Salemi R, Candido S, et al. Gut microbiota and cancer: from pathogenesis to therapy. Cancers (Basel) 2019; 11(1):38

10 Paulos CM, Wrzesinski C, Kaiser A, et al Microbial translocation augm ents the function of adoptively transferred self/tumor-specific CD8+ T cells via TLR4 signaling. J Clin Invest 2007;117:2197-2204

11 Bhatt AP, Redinbo MR, Bultman SJ. The role of the microbiome in cancer development and therapy. CA Cancer J Clin 2017;67(4):326-344

12 Mantovani A. Molecular pathways linking inflammation and cancer. Curr Mol Med 2010;10(4):369-373

13 Ibrahim-Hashim A, Estrella V. Acidosis and cancer: from mechanism to neutralization. Cancer Metastasis Rev 2019;38(1-2): 149-155

14 AsghariHanjani N, Vafa M. The role of IGF-1 in obesity, cardiovascular disease, and cancer. Med J Islam Repub Iran 2019;33:56

15 Kotsantis I, Economopoulou P, Psyrri A, et al Prognostic significance of IGF-1 signaling pathway in patients with advanced non-small cell lung cancer. Ann Oncol 2019;30(suppl_2): ii7-ii13

16 Long J, Zhang CJ, Zhu N, et al. Lipid metabolism and carcinogenesis, cancer development. Am J Cancer Res 2018;8(5):778-791

17 Bonan N, DeCicco-Skinner K. Obesity as a promoter of cancer development and progression. 2018. Available at: https://www.intechopen.com/onlinefirst/obesity-as-a-promoter-of-cancer-development-and-progression. Accessed November 30, 2020

18 Li J, Han Y, Zhang H, et al. The m6A demethylase FTO promotes the growth of lung cancer cells by regulating the $\mathrm{m} 6 \mathrm{~A}$ level of USP7 mRNA. Biochem Biophys Res Commun 2019; 512(3):479-485

19 Wofford JA, Wieman HL, Jacobs SR, Zhao Y, Rathmell JC. IL-7 promotes Glut1 trafficking and glucose uptake via STAT5-mediated activation of Akt to support T-cell survival. Blood 2008;111(4):2101-2111

20 Liberti MV, Locasale JW. The Warburg effect: how does it benefit cancer cells.? Trends Biochem Sci 2016;41(3):211-218

21 GoodwinJ, Neugent ML, Lee SY, et al. The distinct metabolic phenotype of lung squamous cell carcinoma defines selective vulnerability to glycolytic inhibition. Nat Commun 2017;8:15503

22 Sukhatme VP, Chan B. Glycolytic cancer cells lacking 6-phosphogluconate dehydrogenase metabolize glucose to induce senescence. FEBS Lett 2012;586(16):2389-2395

23 Brault C, Schulze A. The role of glucose and lipid metabolism in growth and survival of cancer cells. Recent Results Cancer Res 2016;207:1-22

24 Allott EH, Macias E, Sanders S, et al. Impact of carbohydrate restriction in the context of obesity on prostate tumor growth in the Hi-Myc transgenic mouse model. Prostate Cancer Prostatic Dis 2017;20(2):165-171

25 Doaei S, Gholamalizadeh M, Akbari ME, et al. Dietary carbohydrate promotes cell survival in cancer via the up-regulation of fat mass and obesity-associated gene expression level. Malays J Med Sci 2019;26(2):8:17

26 Hoppe CA, Udam TR, Lauritzen L, Molgaard C, Juul AC, Michaelsen KF. Animal protein intake, serum insulin-like growth factor I, and growth in healthy 2.5-y-old Danish children. Am J Clin Nutr 2004;80:447-452

27 Taha AA, Koshiyama M, Matsumura N, et al. The effect of the type of dietary protein on the development of ovarian cancer. Oncotarget 2018;9(35):23987-23999

28 Romo Ventura E, Konigorski S, Rohrmann S, et al. Association of dietary intake of milk and dairy products with blood concentrations of insulin-like growth factor 1 (IGF-1) in Bavarian adults. Eur J Nutr 2020;59(4):1413:1420

29 Clatici VG, Voicu C, Voaides C, Roseanu A, Icriverzi M, Jurcoane S. Diseases of civilization-cancer, diabetes, obesity and acne-the implication of milk, IGF-1 and mTORC1. Maedica (Bucur) 2018;13(4):273-281

30 Melnik BC, John SM, Schmitz G. Milk is not just food but most likely a genetic transfection system activating mTORC1 signaling for postnatal growth. Nutr J 2013;12:103

31 Tang M. Protein intake during the first two years of life and its association with growth and risk of overweight. Int J Environ Res Public Health 2018;15(8):1742

32 Lippi G, Mattiuzzi C, Cervellin G. Meat consumption and cancer risk: a critical review of published meta-analyses. Crit Rev Oncol Hematol 2016;97:1-14

33 Chai W, Morimoto Y, Cooney RV, et al. Dietary red and processed meat intake and markers of adiposity and inflammation: the multiethnic cohort study. J Am Coll Nutr 2017;36(5): 378-385

34 Ley SH, Sun Q, Willett WC, et al. Associations between red meat intake and biomarkers of inflammation and glucose metabolism in women. Am J Clin Nutr 2014;99(2):352-360

35 Hodgson JM, Ward NC, Burke V, Beilin LJ, Puddey IB. Increased lean red meat intake does not elevate markers of oxidative stress and inflammation in humans. J Nutr 2007;137(2):363-367

36 Ronco AL, Lasalvia-Galante E, Calderón JM, Espinosa E. Dietary iron source and lung cancer risk: a case-control study in Uruguayan men. Multidisciplinary Cancer Invest 2019;3(3): 20:36

37 Muka T, Kraja B, Ruiter R, et al. Dietary mineral intake and lung cancer risk: the Rotterdam Study. Eur J Nutr 2017;56(4): 1637-1646

38 Ward HA, Whitman J, Muller DC, et al. Haem iron intake and risk of lung cancer in the European Prospective Investigation into Cancer and Nutrition (EPIC) cohort. Eur J Clin Nutr 2019; 73(8):1122-1132

39 Arruabarrena-Aristorena A, Zabala-Letona A, Carracedo A. Oil for the cancer engine: the cross-talk between oncogenic signaling and polyamine metabolism. Sci Adv 2018;4(1):r2606

40 Casero RA Jr, Murray Stewart T, Pegg AE. Polyamine metabolism and cancer: treatments, challenges and opportunities. Nat Rev Cancer 2018;18(11):681-695

41 Ouellet V, Weisnagel SJ, Marois J, et al. Dietary cod protein reduces plasma C-reactive protein in insulin-resistant men and women. J Nutr 2008;138(12):2386-2391

42 Sotos Prieto M, Guillen M, Sorlí JV, et al. Meat and fish consumption in a high cardiovascular risk Spanish Mediterranean population. Nutr Hosp 2011;26(5):1033-1040

43 D'Eliseo D, Velotti F. Omega-3 fatty acids and cancer cell cytotoxicity: implications for multi-targeted cancer therapy. J Clin Med 2016;5(2):15

44 Cao C, Kong X, Zhang W, Huang X. Fish intake, dietary polyunsaturated fatty acids, and lung cancer: systematic review and dose response meta-analysis of data from 15 prospective studies. Am J Respir Crit Care Med 2020;201:A7468

45 Merendino N, Costantini L, Manzi L, Molinari R, D’Eliseo D, Velotti F. Dietary $\omega-3$ polyunsaturated fatty acid DHA: a potential adjuvant in the treatment of cancer. BioMed Res Int 2013;2013:310186 
46 Lee JT, Lai GY, Liao LM, et al. Nut Consumption and Lung Cancer Risk: Results from Two Large Observational Studies. Cancer Epidemiol Biomarkers Prec Giugno 2017;26(6):826-836

47 Nordqvist J. The health benefits of almonds. Medical News Today; 2017. Available at: https://www.medicalnewstoday. com/articles/269468.php. Accessed November 30, 2020

48 Zhu F, Du B, Xu B. Anti-inflammatory effects of phytochemicals from fruits, vegetables, and food legumes: a review. Crit Rev Food Sci Nutr 2018;58(8):1260-1270

49 Russo M, Spagnuolo C, Russo GL, et al. Nrf2 targeting by sulforaphane: a potential therapy for cancer treatment. Crit Rev Food Sci Rev 2018;58(8):1391-1405

50 Rakariyatham K, Yang X, Gao Z, et al. Effetto chemiopreventivo sinergico di allil isotiocianato e sulforaphane su cellule di carcinoma polmonare non a piccole cellule. Cibo Funzioni 2019

51 Wu Q-J, Yang G, Zheng W, et al. Assunzione pre-diagnostica di verdure crocifere e sopravvivenza al cancro polmonare tra le donne cinesi. Sci Rep 2015;5-10306

52 Yang YM, Jhanwar-Uniyal M, Schwartz J, et al. N-acetylcysteine conjugate of phenethyl isothiocyanate enhances apoptosis in growth-stimulated human lung cells. Cancer Res 2005; 65(18):8538-8547

53 Janakiram NB, Mohammed A, Madka V, Kumar G, Rao CV. Prevention and treatment of cancers by immune modulating nutrients. Mol Nutr Food Res 2016;60(6):1275-1294

54 Izawa Daiki YK, Tagami OM. Chlorogenic acid regulates apoptosis and stem cell marker-related gene expression in A549 human lung cancer cells. Mol Cell Biochem 2018;441:9

55 Garrett WS. Cancer and the microbiota. Science 2015; 348(6230):80-86

56 Melkonian SC, Daniel CR, Ye Y, Pierzynski JA, Roth JA, Wu X. Glycemic index, glycemic load, and lung cancer risk in Non-Hispanic Whites. Cancer Epidemiol Biomarkers Prev 2016; 25(3):532-539

57 Sereni A, Cesari F, Gori AM, et al. Cardiovascular benefits from ancient grain bread consumption: findings from a double-blinded randomized crossover intervention trial. Int J Food Sci Nutr 2017;68(1):97-103

58 Li X, Ma S, Yang P, et al. Effetti anticancro della curcumina su topi nudi portatori di carcinoma polmonare Sottoinsiemi di cellule A549 cellule SP e NSP. Oncol Lett 2018;16(5)

59 Chen HW, Lee JY, Huang JY, et al. Curcumin inhibits lung cancer cell invasion and metastasis through the tumor suppressor HLJ1. Cancer Res 2008;68(18):7428-7438

60 Chen HW, Yu SL, Chen JJ, et al. Anti-invasive gene expression profile of curcumin in lung adenocarcinoma based on a high throughput microarray analysis. Mol Pharmacol 2004; 65(1):99-110

61 Chen QY, Zheng Y, Jiao DM, et al. Curcumin inhibits lung cancer cell migration and invasion through Rac1-dependent signaling pathway. J Nutr Biochem 2014;25(2):177-185

62 Man S, Zhang L, Cui J, Yang L, Ma L, Gao W. Curcumin enhances the anti-cancer effects of Paris Saponin II in lung cancer cells. Cell Prolif 2018;51(4):e12458

63 Liu F, Gao S, Yang Y, et al. Attività antitumorale della curcumina mediante modulazione dell'apoptosi e dell'autofagia nelle cellule A549 di carcinoma polmonare umano attraverso l'inibizione della via PI3K/Akt/mTOR. Oncol Rep 2018;39(3)

64 Wang C, Song X, Shang M, et al. Curcumin exerts cytotoxicity dependent on reactive oxygen species accumulation in non-small-cell lung cancer cells. Future Oncol 2019;15(11): 1243-1253

65 Zou JY, Su CH, Luo HH, et al. Curcumin converts Foxp3+ regulatory $\mathrm{T}$ cells to $\mathrm{T}$ helper 1 cells in patients with lung cancer. J Cell Biochem 2018;119(2):1420-1428

66 Chen P, Huang H-P, Wang Y, et al. Curcumin overcome primary gefitinib resistance in non-small-cell lung cancer cells through inducing autophagy-related cell death. J Exp Clin Cancer Res 2019;38(1):254

67 Farhood B, Mortezaee K, Goradel NH, et al. Curcumin as an anti-inflammatory agent: implications to radiotherapy and chemotherapy. J Cell Physiol 2019;234(5):5728-5740

68 Bonucci M. Epigallocatechina gallato EGCG- tè verde. ARTOI. Available at: https://www.artoi.it/farmaci-naturali/lepigallocatechina-gallato-egcg/. Accessed November 30, 2020

69 Fujiki H, Suganuma M, Okabe S, et al. Cancer inhibition by green tea. Mutat Res 1998;402(1-2):307-310

70 Rawangkan A, Iida K, Sakai R, Fujiki H, Suganuma M. Abstract 2665: Green tea catechin, EGCG, enhances antitumor immunity by down-regulation of PD-L1 expression in non-small human lung cancer cell lines. Am Assoc Cancer Res 2017;77(3):2665

71 Milligan SA, Burke P, Coleman DT, et al. The green tea polyphenol EGCG potentiates the antiproliferative activity of c-Met and epidermal growth factor receptor inhibitors in non-small cell lung cancer cells. Clin Cancer Res 2009; 15(15):4885-4894

72 Ermakova SP, Kang BS, Choi BY, et al. Epigallocatechin gallate overcomes resistance to etoposide-induced cell death by targeting the molecular chaperone glucose-regulated protein 78 . Cancer Res 2006;66(18):9260-9269

73 Wang J, Sun P, Wang Q, et al. (-)-Epigallocatechin-3-gallate derivatives combined with cisplatin exhibit synergistic inhibitory effects on non-small-cell lung cancer cells. Cancer Cell Int 2019;19:266

74 Vucenik I. Anticancer properties of inositol hexaphosphate and inositol: an overview. J Nutr Sci Vitaminol (Tokyo) 2019;65(suppl) :S18-S22

75 Roh JI, Lee HW. A myo-inositol diet for lung cancer prevention and beyond. J Thorac Dis 2018;10(suppl 33):S3919-S3921

76 Wu C-Y, Ke Y, Zeng Y-F, Zhang Y-W, Yu H-J. Anticancer activity of Astragaluspolysaccharide in human non-small cell lung cancer cells. Cancer Cell Int 2017;17:115

77 Park HJ, Park SH. Induction of apoptosis by ethyl acetate fraction of Astragalus membranaceus in human non-small cell lung cancer cells-apoptosis induction by Astragalus membranaceus. J Pharmacopuncture 2018;21(4):268-276

78 Zhang J-X, Han Y-P, Bai C, Li Q. Notch1/3 and p53/p21 are a potential therapeutic target for APS-induced apoptosis in non-small cell lung carcinoma cell lines. Int J Clin Exp Med 2015;8(8):12539-12547

79 Zhou Y, Hong T, Tong L, et al. Astragalus polysaccharide combined with 10-hydroxycamptothecin inhibits metastasis in non-small cell lung carcinoma cell lines via the MAP4K3/mTOR signaling pathway. Int J Mol Med 2018;42(6):3093-3104

80 Jia L, Lv D, Zhang S, Wang Z, Zhou B. Astragaloside IV inhibits the progression of non-small cell lung cancer through the Akt/

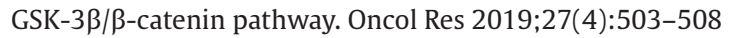

81 Shukla S, Gupta S. Apigenin: a promising molecule for cancer prevention. Pharm Res 2010;27(6):962-978

82 Lu H-F, Chie Y-J, Yang MS, et al. Apigenin induces apoptosis in human lung cancer $\mathrm{H} 460$ cells through caspase- and mitochondria-dependent pathways. Human Exp Toxicol 2010;30(8): 1053-1061

83 Ghitu A, Schwiebs A, Radeke HH, et al. A comprehensive assessment of apigenin as an antiproliferative, proapoptotic, antiangiogenic and immunomodulatory phytocompound. Nutrients 2019;11(4):858

84 Lee Y-M, Lee G, Oh T-I, et al. Inhibition of glutamine utilization sensitizes lung cancer cells to apigenin-induced apoptosis resulting from metabolic and oxidative stress. Int $\mathrm{J}$ Oncol 2016;48(1):399-408

85 Osada M, Imaoka S, Funae Y. Apigenin suppresses the expression of VEGF, an important factor for angiogenesis, in 
endothelial cells via degradation of HIF-1alpha protein. FEBS Lett 2004;575(1-3):59-63

86 Zou J, Yang Y, Yang Y, Liu X. Polydatin suppresses proliferation and metastasis of non-small cell lung cancer cells by inhibiting NLRP3 inflammasome activation via NF-KB pathway. Biomed Pharmacother 2018;108:130-136

87 Zhang Y, Zhuang Z, Meng Q, Jiao Y, Xu J, Saiju FD. Polydatin inhibits growth of lung cancer cells by inducing apoptosis and causing cell cycle arrest. Oncol Lett 2014;7(1):295-301

88 Mele L, Paino F, Papaccio F, et al. A new inhibitor of glucose-6-phosphate dehydrogenase blocks pentose phosphate pathway and suppresses malignant proliferation and metastasis in vivo. Cell Death Dis 2018;9(5):572

89 Fuggetta MP, Migliorino MR, Ricciardi S, et al. Prophylactic dermatologic treatment of afatinib-induced skin toxicities in patients with metastatic lung cancer: a pilot study. Sci Vol 2019 (e-pub ahead of print) doi: /2019/9136249

90 Abdul QA, Choi RJ, Jung HA, Choi JS. Health benefit of fucosterol from marine algae: a review. J Sci Food Agric 2016; 96(6):1856-1866

91 Mao Z, Shen X, Dong P, et al. Fucosterol exerts antiproliferative effects on human lung cancer cells by inducing apoptosis, cell cycle arrest and targeting of Raf/MEK/ERK signalling pathway. Phytomedicine 2018;61:152809

92 Fernando IPS, Jayawardena TU, Kim HS, et al. Beijing urban particulate matter-induced injury and inflammation in human lung epithelial cells and the protective effects of fucosterol from Sargassum binderi (Sonder ex J. Agardh) Environ Res 2019;172:150-158

93 Yoo MS, Shin JS, Choi HE, et al. Fucosterol isolated from Undaria pinnatifida inhibits lipopolysaccharide-induced production of nitric oxide and pro-inflammatory cytokines via the inactivation of nuclear factor-кB and p38 mitogen-activated protein kinase in RAW264.7 macrophages. Food Chem 2012;135(3):967-975

94 Li Y, Li X, Liu G, et al. Fucosterol attenuates lipopolysaccharideinduced acute lung injury in mice. J Surg Res 2015;195(2): 515-521

95 Ayeka PA. Potential of mushroom compounds as immunomodulators in cancer immunotherapy: a review. Evid Based Complement Alternat Med 2018

96 Fernandez SP, Ferriol P, Gavela ST, Sureda A. Mushrooms reishi (Ganoderma lucidum), shiitake (Lentinula edodes), maitake (Grifola frondosa ) In Nonvitamin and Nonmineral Nutritional Supplements. 1st ed; 2019 517-526

97 Zhang Y, Zhang M, Jiang Y, et al. Lentinan as an immunotherapeutic for treating lung cancer: a review of 12 years clinical studies in China. J Cancer Res Clin Oncol 2018;144(11): 2177-2186

98 Masuda Y, Inoue M, Miyata A, Mizuno S, Nanba H. Maitake beta-glucan enhances therapeutic effect and reduces myelosuppression and nephrotoxicity of cisplatin in mice. Int Immunopharmacol 2009;9(5):620-626

99 Cao Y, Xu X, Liu S, Huang L, Gu J. Ganoderma: a cancer immunotherapy review. Front Pharmacol 2018;9:1217

100 Jeon SM, Shin EA. Exploring vitamin D metabolism and function in cancer. Exp Mol Med 2018;50(4):20

101 Liu W, Zhang L, Xu H-J, et al. The anti-inflammatory effects of vitamin D in tumorigenesis. Int J Mol Sci 2018;19(9):2736

102 Akiba T, Morikawa T, Odaka M, et al. Vitamin D supplementation and survival of patients with non-small cell lung cancer: a randomized, double-blind, placebo-controlled trial. Clin Cancer Res 2018;24(17):4089-4097

103 Chen S, Sims GP, Chen XX, Gu YY, Chen S, Lipsky PE. Modulatory effects of 1,25-dihydroxyvitamin D3 on human B cell differentiation. J Immunol 2007;179(3):1634-1647
104 Sommer A, Fabri M, Vitamin D. Vitamin D regulates cytokine patterns secreted by dendritic cells to promote differentiation of IL-22-producing T cells. PLoS One 2015;10(6):e0130395

105 Kouhi Habibi N, Shabestani Monfared A, Ebrahimnejad Gorji K, et al. The protective effects of melatonin on blood cell counts of rectal cancer patients following radio-chemotherapy: a randomized controlled trial. Clin Transl Oncol 2019;21(6): 745-752

106 Carrillo-Vico A, Calvo JR, Abreu P, et al. Evidence of melatonin synthesis by human lymphocytes and its physiological significance: possible role as intracrine, autocrine, and/or paracrine substance. FASEB J 2004;18(3):537-539

107 Anwar MM, Mahfouz HA, Sayed AS. Potential protective effects of melatonin on bone marrow of rats exposed to cytotoxic drugs. Comp Biochem Physiol A Mol Integr Physiol 1998; 119(2):493-501

108 Tóth B, Lantos T, Hegyi P, et al. Ginger (Zingiber officinale): An alternative for the prevention of postoperative nausea and vomiting. A meta-analysis. Phytomedicine 2018;50(15):8-18

109 Tahir M, Khokhar MA, Ilyas S, Qamar S. Chemotherapy induced nausea and vomiting; efficacy of the ginger to standard therapies as prophylaxis for chemotherapy induced nausea and vomiting in cancer patients. Prof Med J 2019;26(3):455-460

110 Khan L, Simpson WG, Ginger as a possible alternative treatment for gastroparesis. Chronic Comp Alt Integr Med 2019

111 Soltani E, Jangjoo A, Afzal Aghaei M, Dalili A. Effects of preoperative administration of ginger (Zingiber officinale Roscoe) on postoperative nausea and vomiting after laparoscopic cholecystectomy. J Tradit Complement Med 2017;8(3):387-390

112 De Grandis D. Acetyl-L-carnitine for the treatment of chemotherapy-induced peripheral neuropathy: a short review. CNS Drugs 2007;21(suppl 1) :39-43, discussion 45-46

113 De Grandis D, Santoro L, Di Benedetto P. L-Acetylcarnitine in the treatment of patients with peripheral neuropathies : a short term, double-blind clinical study of 426 patients. Clin Drug Investig 1995;10(6):317-322

114 Di Stefano G, Di Lionardo A, Galosi E, Truini A, Cruccu G. Acetyl-L-carnitine in painful peripheral neuropathy: a systematic review. J Pain Res 2019;12:1341-1351

115 Barton DL. Ilginseng combatte l'affaticamento nei malati di cancro. Riv Online Forefront Mayo Clin Cancer Cent 2012

116 Majeed M, Majeed S, Narayanan NK, Nagabhushanam K. A pilot, randomized, double-blind, placebo-controlled trial to assess the safety and efficacy of a novel Boswellia serrata extract in the management of osteoarthritis of the knee. Phytother Res 2019;33(5):1457-1468

117 Pinzon R, Wijaya V. Curcuma longa e Boswellia serrata per migliorare lo stato funzionale nei pazienti con osteoartrosi: dalle prove da banco a quelle al letto. Asian J Med Sci 2019; 10(5):1-5

118 Gokaraju GR, Gokaraju RR, Gokaraju VKRR, Golakoti T, Bhupathiraju K, Alluri VKR. Synergistic anti-inflammatory compositions comprising Boswellia serrata extract. Google brevetti. Available at: https://patents.google.com/patent/ US20190175678A1/en. Accessed November 30, 2020

119 Cirillo N, Vicidomini A, McCullough M, et al. A hyaluronic acid-based compound inhibits fibroblast senescence induced by oxidative stress in vitro and prevents oral mucositis in vivo. J Cell Physiol 2015;230(7):1421-1429

120 Giacomelli I, Scartoni D, Fiammetta M, et al. Oral lapacho-based medication: an easy, safe, and feasible support to prevent and/ or reduce oral mucositis during radiotherapy for head and neck cancer. Nutr Cancer 2015;67(8):1247-1253

121 Gangadharan A, Choi SE, Hassan A, et al. Protein calorie malnutrition, nutritional intervention and personalized cancer care. Oncotarget 2017;8(14):24009-24030 
122 Seiler A, Jenewein J. Resilience in Cancer patients. Davanti. Front Psychiatry 2019;10:208

123 Aldarouish M, Su X, Qiao J, et al. Immunomodulatory effects of chemotherapy on blood lymphocytes and survival of patients with advanced non-small cell lung cancer. Int J Immunopathol Pharmacol 2019;33:2058738419839592

124 Gale RP. Antineoplastic chemotherapy myelosuppression: mechanisms and new approaches. Exp Hematol 1985; 13(suppl 16):3-7

125 Cheng Y, Wu R, Cheng M, et al. Carboplatin-induced hematotoxicity among patients with non-small cell lung cancer: analysis on clinical adverse events and drug-gene interactions. Oncotarget 2016;8:32228:32236

126 Comitato editoriale PDQ di supporto e cure palliative. Cancer Pain (PDQ ${ }^{\circledR}$ ): versione Health Professional. 30 ottobre 2019.
In: Sintesi delle informazioni sul cancro PDQ. Bethesda (MD): National Cancer Institute (US); 2002. Disponibile a: https:// www.ncbi.nlm.nih.gov/books/NBK65949/

127 Deek MP, Kim S, Ahmed I, et al. Prognostic impact of missed chemotherapy doses during chemoradiation therapy for non-small cell lung cancer.AmJClin Oncol 2018;41(4):362-366

128 Keith RL. Carcinoma del polmone. Manual Version Prof; 2018. Available at: https://www.msdmanuals.com/it-it/professionale/ malattiepolmonari/tumori-del-polmone/carcinoma-delpolmone. Accessed November 30, 2020

129 Liu z, Gao Y, Hao F, et al. Secretomes are a potential source of molecular targets for cancer therapies and indicate that APOE is a candidate biomarker for lung adenocarcinoma metastasis. Mol Biol Rep 2014;41(11):7507-7523 